This item was submitted to Loughborough's Research Repository by the author.

Items in Figshare are protected by copyright, with all rights reserved, unless otherwise indicated.

\title{
Detection of volatile organic compounds in breath using thermal desorption electrospray ionization-ion mobility-mass spectrometry
}

PLEASE CITE THE PUBLISHED VERSION

http://dx.doi.org/10.1021/ac9027593

\section{PUBLISHER}

(c) American Chemical Society

\section{VERSION}

AM (Accepted Manuscript)

\section{PUBLISHER STATEMENT}

This work is made available according to the conditions of the Creative Commons Attribution-NonCommercialNoDerivatives 4.0 International (CC BY-NC-ND 4.0) licence. Full details of this licence are available at: https://creativecommons.org/licenses/by-nc-nd/4.0/

\section{LICENCE}

CC BY-NC-ND 4.0

\section{REPOSITORY RECORD}

Reynolds, James C., Gavin J. Blackburn, C. Guallar-Hoyas, Victor Moll, Victor Bocos-Bintintan, G. Kaur-Atwal, Mark D. Howdle, et al.. 2019. "Detection of Volatile Organic Compounds in Breath Using Thermal Desorption Electrospray lonization-ion Mobility-mass Spectrometry”. figshare. https://hdl.handle.net/2134/16027. 


\title{
Detection of Volatile Organic Compounds in Breath
}

\section{Using Thermal Desorption Electrospray}

\section{Ionization-Ion Mobility-Mass Spectrometry}

\author{
J. C. Reynolds, ${ }^{*}$ G. J. Blackburn, C. Guallar-Hoyas, V. H. Moll, V. Bocos-Bintintan, G. Kaur-Atwal, \\ M. D. Howdle, E. L. Harry, L. J. Brown, C. S. Creaser, and C. L. P. Thomas \\ Centre for Analytical Science, Department of Chemistry, Loughborough University, Loughborough, \\ Leicestershire,
}

A thermal desorption unit has been interfaced to an electrospray ionization-ion mobilitytime-of-flight mass spectrometer. The interface was evaluated using a mixture of six model volatile organic compounds which showed detection limits of $<1$ ng sample loaded onto a thermal desorption tube packed with Tenax, equivalent to sampled concentrations of $4 \mu \mathrm{g}$ L-1. Thermal desorption profiles were observed for all of the compounds, and ion mobility-mass spectrometry separations were used to resolve the probe compound responses from each other. The combination of temperature programmed thermal desorption and ion mobility improved the response of selected species against background ions. Analysis of breath samples resulted in the identification of breath metabolites, based on ion mobility and accurate mass measurement using siloxane peaks identified during the analysis as internal lockmasses.

\section{Introduction}

The development of electrospray ionization (ESI) by Fenn and co-workers in 19841 enabled the routine analysis of macromolecules and revolutionized the role mass spectrometry plays in the analysis of biological samples. It was suggested as early as 19862 that volatile organic compounds (VOCs) could also be ionized and detected with a high degree of sensitivity using ESI. However the first effective demonstration of the application of ESI to VOC analysis was not reported until 1994,3 when an ESI source was interfaced to an ion mobility spectrometer. Hill and co-workers further developed this approach, termed, secondary electrospray ionization (SESI),4 in conjunction with a hybrid ion mobility-quadrupole mass spectrometer, which they used to study a number of illicit 
drugs. The charged droplets from the electrospray were reacted with the VoCs in a reaction cell placed immediately before the ion mobility drift cell. This work demonstrated that SESI could be used as an effective ionization method for both gas chromatography (GC) and liquid chromatography- mass spectrometry (LC-MS) experiments and that it was also more sensitive than standard electrospray for the analysis of VOCs. SESI was also later used to analyze vapors from explosives with detection limits at the sub-parts per trillion level, further demonstrating the high sensitivity of the approach.5 Recent work has shown that VOCs may be detected down to parts per quadrillion levels using electrospray ionization and that the ESI source parameters can be optimized to give selectivity toward specific ion species.6 Cooks et al. proposed an alternative approach, called extractive electrospray ionization (EESI), where an electrospray source was placed in close proximity to a nebulized sample spray. 7 The two sprays overlap, and the charged droplets from the electrospray collide with the neutral droplets resulting in the extraction of analyte molecules from the neutral droplets into the charged droplets, which are then ionized as they desolvate. Initially this technique was used to look at trace level pesticides and explosives in urine, river water, and milk. No prior sample preparation was required, due to the extractive nature of the process, and limits of detection down to picomolar levels were reported. EESI has since been used to analyze a wide range of VOCs emitted from different sources such as fruit, 8 perfumes,9,10 and human skin.11 EESI-MS has also been used to analyze human breath.12,13 A study conducted in 2007 showed that EESI could be used to follow the concentration of an exhaled breath metabolite (urea) from breath to breath.12 In the same year, Zenobi and co-workers used EESI to look directly at exhaled breath and were able to detect involatile species such as carbohydrates which were present after eating a meal.13 The analysis of breath samples using gas chromatography/ mass spectrometry (GC/MS) has shown that a large number of VOCs may be detected and that VOC profiles in human breath are characterized by a huge degree of complexity. A significant feature of VOC profiles in breath is the wide concentration range over which they are detected, with many compounds of interest present at concentrations below the limits of detection for direct breath analysis.14 In order to detect the VOCs which are present in breath at these lower levels, a preconcentration technique is required. The use of thermal desorption (TD) tubes as a method of trapping and preconcentrating VOCs from the gas phase has been widely used in conjunction with GC/MS instrumentation.14-16 Thermal desorption has 
also been hyphenated to ion mobility spectrometry and has been shown to be able to distinguish between volatile and semivolatile biogenic amines based on their thermal desorption properties.17 In addition to being able to preconcentrate VOCs, TD tubes enable samples to be stored and easily transported from the point of collection to the analytical laboratory. GC/MS analysis of breath samples is a time-consuming process, with typical analysis times of an hour. If the separation could be performed faster, then breath analysis would be much more viable as a screening technique for large numbers of breath samples. Ion mobility (IM) spectrometry18 is a gas phase technique that separates analyte on the millisecond time scale. IM has previously been used widely as a stand alone system with $63 \mathrm{Ni}$ atmospheric pressure chemical ionization for the detection of a range of different VOCs19 and has been coupled to GC separations for the analysis of breath metabolites.20 IM can also be hyphenated to electrospray ionization for the analysis of involatile species.21 The time scale of IM separations makes it ideally compatible for hyphenation with time-of-flight mass spectrometry (TOF-MS). The recent development of commercially available hybrid electrospray ion mobility-mass spectrometers has enabled the fast, orthogonal separations associated with IM and MS to be applied in a widespread way to biological analysis.22-24 This work describes the first interfacing of a thermal desorption unit to an IM-MS using an ESI source. The potential of TD-ESI-IM-MS for the rapid screening of breath volatiles as an alternative technique to TD-GC/MS is demonstrated.

\section{EXPERIMENTAL SECTION}

\section{Instrumentation.}

The electrospray source of a Waters (Manchester, U.K.) Synapt ion mobility-quadrupole time-of-flight mass spectrometer was modified to accommodate the outlet from a Markes International (Swansea, U.K.) UNITY 1 thermal desorption unit. This was accomplished by removing the lockspray baffle plate and the reference sprayer assembly. The front of the source was opened to allow the heated transfer line of the UNITY containing a $0.25 \mathrm{~mm}$ i.d. fused silica capillary to be introduced into the ESI source. (Note: care needed to be exercised during this process as it was necessary to deactivate the source interlock switches.) The outlet of the transfer line capillary from the UNITY was positioned approximately $0.5-1 \mathrm{~cm}$ from the sample cone of the mass spectrometer and aligned to a point approximately $5 \mathrm{~mm}$ from the electrospray emitter, so that the gas stream from 
the thermal desorber was entrained toward the sample cone by the desolvation gas. Figure 1 shows a schematic of the instrument setup and the positioning of the transfer line outlet in relation to the sample cone. The UNITY thermal desorber carrier gas was helium, which flowed through the system at a rate of approximately $3 \mathrm{~mL} \min -1$. Samples were trapped on thermal desorption tubes, containing approximately $150 \mathrm{mg}$ of Tenax. The thermal desorption tubes were conditioned by heating at $300{ }^{\circ} \mathrm{C}$ for $6 \mathrm{~h}$ with a flow rate of $100 \mathrm{~mL}$ min-1. Analytes were desorbed from the Tenax at $300{ }^{\circ} \mathrm{C}$ for $5 \mathrm{~min}$ and retained on a cold trap held at $-10^{\circ} \mathrm{C}$. The secondary desorption rate from the cold trap was varied between 1 and $12{ }^{\circ} \mathrm{C} \mathrm{S-1}$ for breath samples and was set at $40{ }^{\circ} \mathrm{C} \mathrm{S-1}$ for the standard samples run to characterize the system. The cold trap was heated to a desorption temperature of $300{ }^{\circ} \mathrm{C}$ and was held for $5 \mathrm{~min}$. The electrospray source was set to operate in the positive mode with conditions as follows: capillary voltage $3 \mathrm{kV}$, cone voltage $20 \mathrm{~V}$, source temperature $120{ }^{\circ} \mathrm{C}$, desolvation temperature $300{ }^{\circ} \mathrm{C}$, desolvation gas was nitrogen at a flow rate of $800 \mathrm{~L} \mathrm{~h}_{-1}$, cone gas was also nitrogen set at $20 \mathrm{~L} \mathrm{~h}$-1. The electrospray solvent was $0.1 \%$ formic acid in 50/50 (v/v) methanol/water infused into the source at $5 \mu \mathrm{L} \mathrm{min}$-1. The ion mobility cell parameters were varied depending on the drift times of the analytes investigated. The T-wave height and IM cell gas pressure were varied between 7.0 and $11.5 \mathrm{~V} / \mathrm{cm}$ and 20 and 40 units, respectively.

Sample Preparation. A mixture of six standards was prepared by mixing equal amounts (100 $\mu \mathrm{L}$ ) of 2-butanone, 2-nonanone, heptaldehyde, capronaldehyde, 2-octanol, and 2hexanol into high- purity dichloromethane (100 $\mu \mathrm{L}$ of each standard and $400 \mu \mathrm{L}$ of DCM). Aliquots of this mixture were loaded onto thermal desorption tubes either through direct spiking $(0.1 \mu \mathrm{L})$ or by evaporating $(0.1 \mu \mathrm{L})$ into a headspace vial and then pumping the vapor from the headspace into the adsorbent tube using a venturi pump. Breath samples were collected from a healthy volunteer using an adaptive sampling technique described elswhere.14 The work with human participants was conducted in accordance with the ethical principles of Good Clinical Practice and the Declaration of Helsinki. The local ethics committee (Loughborough University) approved the protocol before commencement of the study.

RESULTS

Thermal Desorption of Standard Compounds. 
In order to determine whether mass spectra could be obtained from the thermal desorption of VOCs from thermal desorption tubes packed with Tenax, the system was initially tested using $0.1 \mu \mathrm{L}$ of a 10 ppmv solution of the six component mixture spiked onto a previously blanked tube. Figure 2 shows the selected ion thermal desorption profiles for each of these species. All of the compounds were detected in the mass spectrum. Butan-2-one and nonan-2- one yielded the most intense responses and the highest signal to- noise (peak to peak) ratio, in line with their higher proton affinities. The alcohols and aldehydes showed significantly lower responses but can still clearly be seen to be desorbed from their thermal desorption profiles, which show elevated levels coinciding with the cold trap firing. Limits of detection were determined from the signalto-noise ratios obtained and were as follows: butan-2- one $0.085 \mathrm{ng}$, nonan-2-one 0.03 ng, 2-octanol $0.31 \mathrm{ng}$, 2-hexanol $0.65 \mathrm{ng}$, heptaldehyde $0.48 \mathrm{ng}$, and capronaldehyde $0.37 \mathrm{ng}$. Figure 2 also shows the differences in the thermal desorption profiles for each of the different species. The most volatile species, 2-butanone (boiling point (BP) $80{ }^{\circ} \mathrm{C}$ ) was desorbed rapidly with the desorption profile maximum at $0.458 \mathrm{~min}$ from the start of cold trap heating. This contrasts with the relatively less volatile species, octanol (BP 195 ${ }^{\circ} \mathrm{C}$ ) with a desorption profile maximum at $0.502 \mathrm{~min}$ from the start of the cold trap heating cycle. Overall, Figure 2 indicates that partial resolution is possible between the thermal desorption profiles, for example, octanol and 2-butanone responses. This observation suggests that careful control of the temperature programming of the thermal desorption may enable better separation of species based on their volatility, giving an extra degree of selectivity to the TD-ESI-IM-MS approach. Optimization of the ion mobility cell was also performed by spiking the six model compounds onto a Tenax tube. Reducing the traveling wave height to $7.0 \mathrm{~V}$ and increasing the nitrogen pressure in the IM drift cell to 40 units, 0.91 mbar resulted in the best IM separation. The resulting mass-selected ion mobility spectra are shown in Figure 3 corresponding to the desorption of $0.80-0.83 \mathrm{ng}$ of the model compounds from the Tenax tube. The partial resolution in the mobility domain could be exploited to improve the relative intensity of specific ion species. The total ion mobility trace in Figure 3 indicates that the ion mobility can be used to enhance the response from the probe compounds relative to the background response.

Breath Sample Analysis. 
The optimum parameters for the ion mobility drift cell identified from the studies with the six probe compounds were used for the analysis of breath samples collected on Tenax tubes. Figure 4 shows an example of the total ion desorption profile obtained from a breath sample against the tube blank. The strong response obtained from the breath samples is evident, and further analysis in the mass and mobility domains was undertaken. Figure 5 shows the mass spectrum obtained from a blank thermal desorption tube (Figure 5A) and the TD-IM-MS spectrum of a breath sample (Figure 5B). Figure $5 \mathrm{C}$ shows the background subtracted mass spectrum obtained over the expanded mass range $m / z 50-250$. The mass spectrum obtained from the blank tube indicted the presence of common background interferences (e.g., $m / z$ 158.0842, 141.0549, and 214.1622). The ion at $m / z 170.1556$ was not removed by background subtraction and originated from the thermal desorption process. Figure 5B shows a large number of peaks that were not present in the blank analysis. Of interest were the siloxanes, identified on the basis of $m / z$ values and characteristic isotope patterns. The source of these species in the breath sample has yet to be unequivocally determined, but the most likely sources are probably the silicone seals used in the face mask and silicone tubing used to connect the face mask to the air supply. Hexamethylcyclotrisiloxane $(m / z$ 223.0642), octamethylcyclotetrasiloxane $(m / z \quad 297.0793), \quad$ and decamethylcyclopentasiloxane $(m / z \quad 371.0882)$ were identified, with decamethylcyclopentasiloxane the base peak in the mass spectrum. Since the exact masses of these species are known they can be used as internal lockmasses to calibrate the mass spectra. The protonated molecular ion of hexamethylcyclotrisiloxane (exact mass ) $m / z$ 223.0642) was selected as a lockmass because it was present at an intensity that did not cause the detector of the mass spectrometer to go into deadtime and hence affect the mass accuracy of the experiment. The limited dynamic range of the IM-MS in the ion mobility mode of operation prevented the higher intensity siloxanes from being adopted as lockmasses. In addition to the siloxanes, there are significant numbers of other peaks attributable to breath VOC and metabolites (Figure 5C), the majority of which were observed at lower $m / z$ ratios. The internal lockmass calibration generated high enough mass accuracies for the prediction of elemental composition (MassLynx software, Waters Micromass U.K.). Metabolites were identified with a high degree of mass accuracy $(<6 \mathrm{ppm})$, providing extra confidence in metabolite assignments. For example, the major breath metabolite acetone ${ }_{25}$ was identified by the 
$[\mathrm{M}+\mathrm{H}]_{+}$ion at $m / z 59.0491$ (expected 59.0497), a mass accuracy of $1.4 \mathrm{ppm}$. Five replicate breath samples were analyzed using TD-ES-IM-MS; acetone was detected in all five samples. The reproducibility of the mass measurement accuracy was calculated using the siloxane peak as a lockmass with an average $m / z$ ratio of 59.0494 and with a relative standard deviation of $9.6 \cdot 10-7 \%$. The mean intensity of the acetone peak was found to be $1.35 \cdot 10_{4}$ counts with a relative standard deviation of $13.5 \%$. These data show good reproducibility and mass measurement accuracy between samples. The ion mobility separation can be used to enhance the mass spectrum for a specific metabolite, and an example of this is demonstrated in Figure 6. Parts A and B of Figure 6 contrast the total ion mobility spectrum and the selected ion mobility response for acetone. The relative intensity of the acetone peak in the mass spectrum (Figure $6 \mathrm{C}$ ) obtained by integrating the 200 scans of the ion mobility spectrum was $6 \%$. The acetone peak in the mass spectrum isolated from between 1.89 and $2.56 \mathrm{~ms}$ (Figure 6D) was much enhanced with higher mass interferences eliminated and a significant increase in the relative intensity $(60 \%)$ of the acetone $[\mathrm{M}+\mathrm{H}]+$ response.

\section{CONCLUSIONS}

This work shows that thermal desorption can be successfully hyphenated to an electrospray ion mobility-time-of-flight mass spectrometer. The TD-ESI-IM-MS technique has been used to study standard compounds, volatile analytes, and metabolites sampled from human breath. The technique has been shown to be able to detect subnanogram levels of analyte desorbed from an adsorbent tube. Control of the temperature program used in the thermal desorption process appears to have potential to introduce a time domain to those of mass and mobility as part of the separation process to impart additional selectivity to the technique. Volatile breath metabolites were isolated and identified using accurate mass analysis. Such accuracy is sufficient to allow reliable elemental composition predictions to be made. These initial data demonstrate the viability of using thermal desorption with ion mobility-mass spectrometry. The ion mobility cell generated an additional degree of selectivity, and partial resolution of the analyte species was achieved with background interferences suppressed and spectral quality improved. This work establishes the potential for increasing analysis speed in breath screening by combining TD with IM-MS. Indeed, with further advances in the design of IMMS instrumentation, this could open the possibility of TD-IM-MS becoming a significantly 
faster alternative for the rapid screening of VOCs to conventional GC based approaches. Furthermore, a move to adsorbent based sampling in conjunction with IM-MS addresses one of the significant barriers to implementing widespread breathbased screening and research. Namely, samples from a large geographic region may be analyzed by a single facility, significantly enhancing the capability in breath research and the development of new diagnostic techniques.

\section{ACKNOWLEDGMENT}

The authors gratefully acknowledge the support given to G. J. Blackburn, C. Guallar-Hoyas and E. L. Harry by AstraZeneca. G. J. Blackburn also gratefully acknowledges his BBSRC CASE studentship. M. D. Howdle acknowledges his EPSRC CASE studentship supported by GlaxoSmithKline. L. J. Brown acknowledges the support provided by Owlstone Ltd. V. H. Moll, V. Bocos- Bintintan were supported jointly by John Hoggs Technical Solutions Shell Global Solutions and the Technology Strategy Board.

\section{References}

(1) Yamashita, M.; Fenn, J. B. J. Phys. Chem. 1984, 117, 4451.

(2) Whitehouse, C. M.; Levin, F.; Meng, C. K.; Fenn, J. B. Proceedings of the 34th ASMS Conference on Mass Spectrometry and Allied Topics, Denver, CO, 1986; p 507.

(3) Chen, Y. H.; Hill, H. H.; Wittmer, D. P. J. Microcolumn Sep. 1994, 6, 1994.

(4) Wu, C.; Siems, W. F.; Hill, H. H. Anal. Chem. 2000, 72, 396.

(5) Tam, M.; Hill, H. H. Anal. Chem. 2004, 76, 2741.

(6) Dillon, L.; Fielden, P. R.; Goddard, N. J.; Thomas, C. L. P. Analyst Submitted for publication.

(7) Chen, H.; Venter, A.; Cooks, R. G. Chem. Commun. 2006, 2042.

(8) Chen, H.; Sun, Y.; Wortmann, A.; Gu, H.; Zenobi, R. Anal. Chem. 2007, 79, 1447.

(9) Chingin, K.; Gamez, G.; Chen, H.; Zhu, L.; Zenobi, R. Rapid Commun. Mass Spectrom. 2008, 22, 2009.

(10) Chingin, K.; Chen, H.; Gamez, G.; Zhu, L.; Zenobi, R. Anal. Chem. 2009, 81, 123.

(11) Chen, H.; Yang, S.; Wortmann, A.; Zenobi, R. Angew. Chem., Int. Ed. 2007, 46, 759. 
(12) Martinez-Lozano, P.; Fernandez de la Mora, J. Int. J. Mass Spectrom. 2007, 265, 6872.

(13) Chen, H.; Wortmann, A.; Zhang, W.; Zenobi, R. Angew. Chem., Int. Ed. 2007, 46, 580.

(14) Basanta, M.; Koimtzis, T.; Singh, D.; Wilson, I.; Thomas, C. L. P. Analyst 2007, 132, 153.

(15) Van Berkel, J. J. B. N.; Dalling, J. W.; Moeller, G. M.; Godschalk, R. W. L.; Moonen, E.; Wouters, E. F. M.; Van Schooten, F. J. J. Chromatogr., B 2008, 861, 101.

(16) Harper, M. J. Chromatogr., A 2000, 885, 129.

(17) Karpas, Z.; Chaim, W.; Gdalevsky, R.; Tilman, B.; Lorber, A. Anal. Chim. Acta 2002, $474,115$.

(18) Creaser, C. S.; Griffiths, J. R.; Bramwell, C. J.; Noreen, S.; Hill, C. A.; Thomas, C. L. P. Analyst 2004, 129, 984.

(19) Steinfeld, J. I.; Wormhoudt, J. Annu. Rev. Phys. Chem. 1998, 49, 203.

(20) Ruzsanyi, V.; Baumbach, J. A.; Sielemann, S.; Litterst, P.; Westhoff, M.; Freitag, L. J. Chromatogr., A 2005, 1084, 145.

(21) Budimir, N.; Weston, D. J.; Creaser, C. S. Analyst 2007, 132, 34-40.

(22) Pringle, S. D.; Giles, K.; Wildgoose, J. L.; Williams, J. P.; Slade, S. E.; Talassinos, K.; Bateman, R. H.; Bowers, M. T.; Scrivens, J. H. Int. J. Mass Spectrom. 2007, 261, 1.

(23) Weston, D. J.; Bateman, R.; Wilson, I. D.; Wood, T. R.; Creaser, C. S. Anal. Chem. 2005, 77, 7572.

(24) Kaur-Atwal, G.; Weston, D. J.; Green, P. S.; Crosland, S.; Bonner, P. L. R.; Creaser, C. S. Rapid Commun. Mass Spectrom. 2007, 21, 1131. 


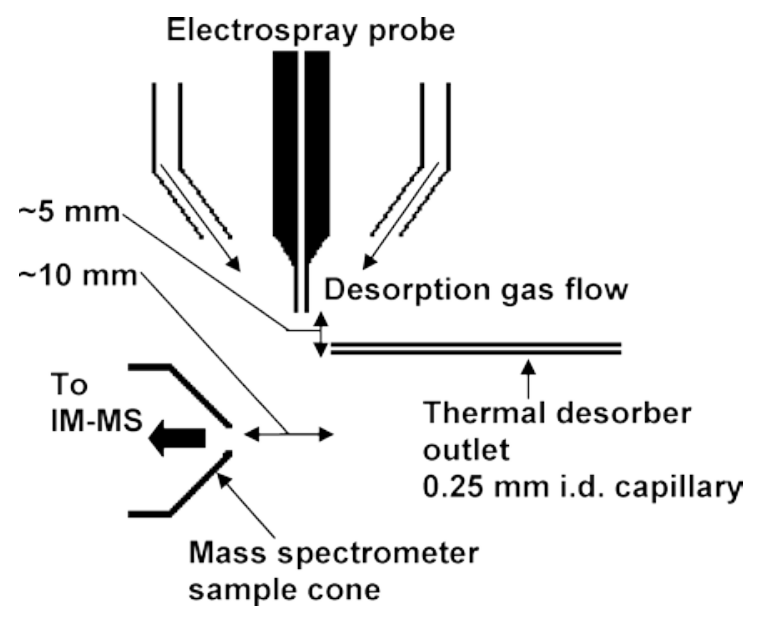

Figure 1. Schematic of the mass spectrometer electrospray source showing the positioning of the thermal desorption unit outlet capillary with respect to the sample inlet cone. 


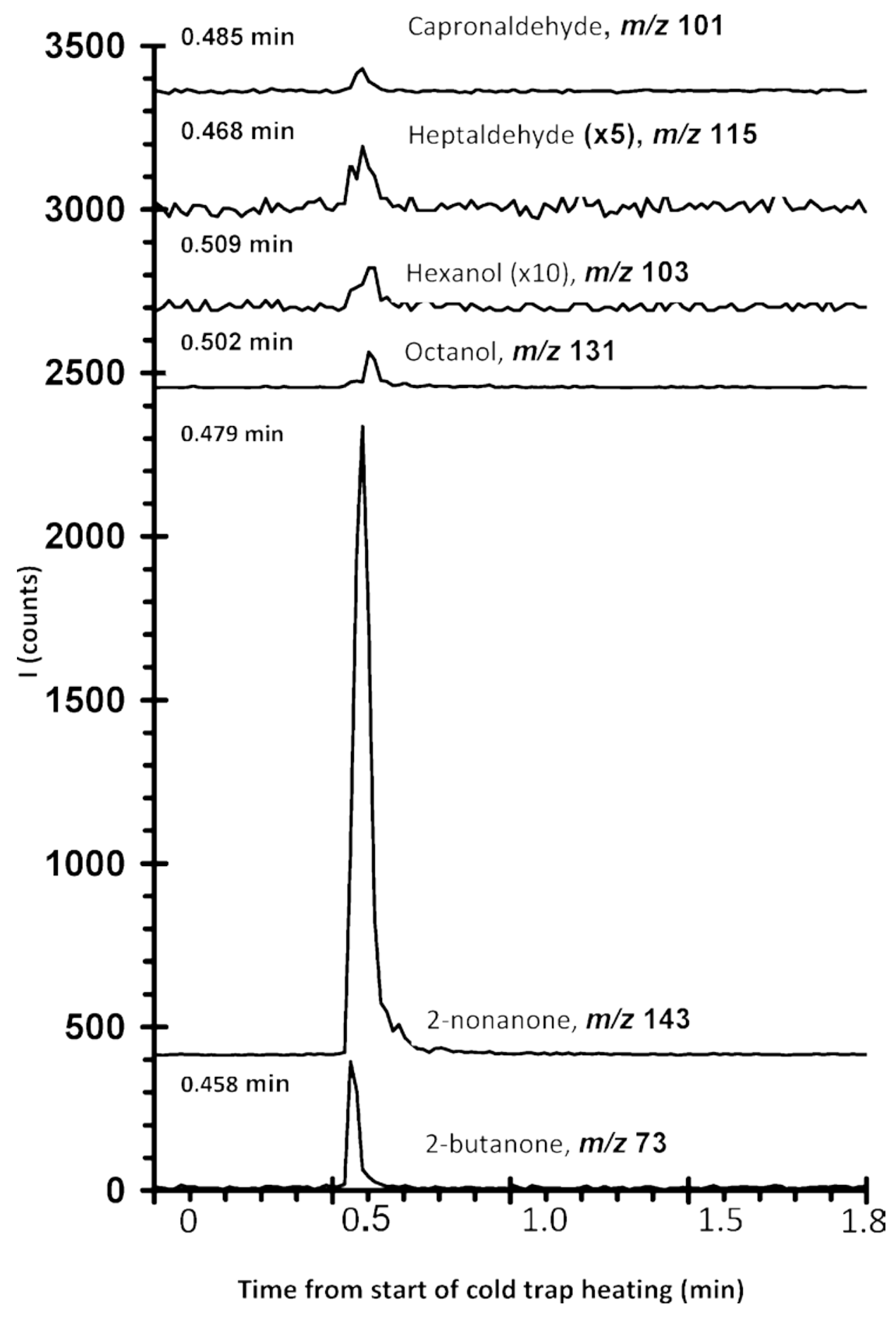

Figure 2. Offset mass selected thermal desorption profiles for the six probe compounds (on-trap masses ) 0.805-0.832 ng). These responses clearly illustrate the different ionization yields observed for the different species, the signal-to-noise (ptp) ratio, and the different desorption time maxima, indicating the potential of introducing an additional degree of separation. 


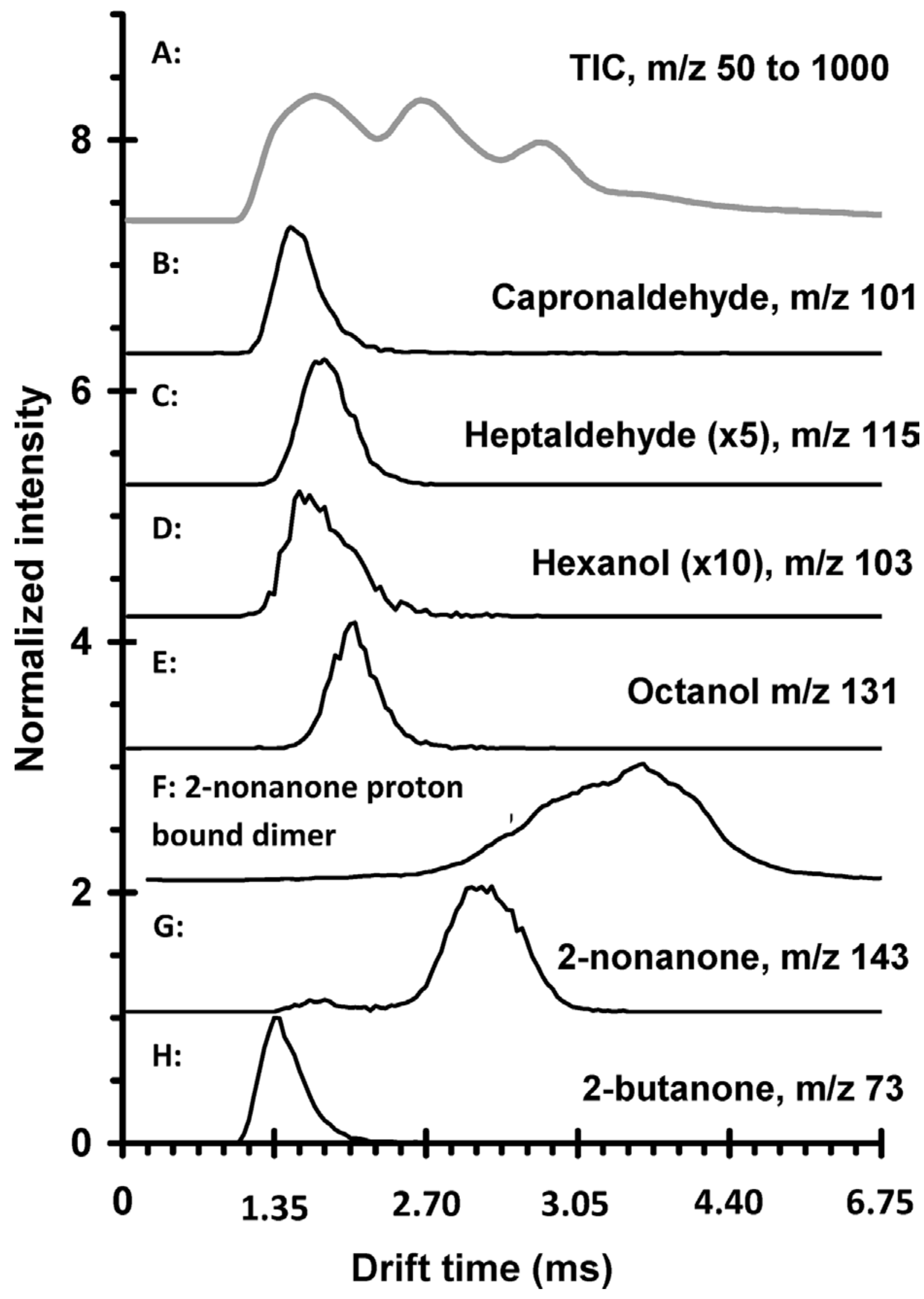

Figure 3. Offset normalized selected ion mobility spectra of six model compounds and the total ion mobility spectrum: (A) total IM spectrum, (B) capronaldhyde, (C) 
heptaldehyde, (D) hexanol, (E) octanol, (F) 2-nonanone proton bound dimer, (G) 2nonanone, and $(\mathrm{H})$ 2-butanone. 


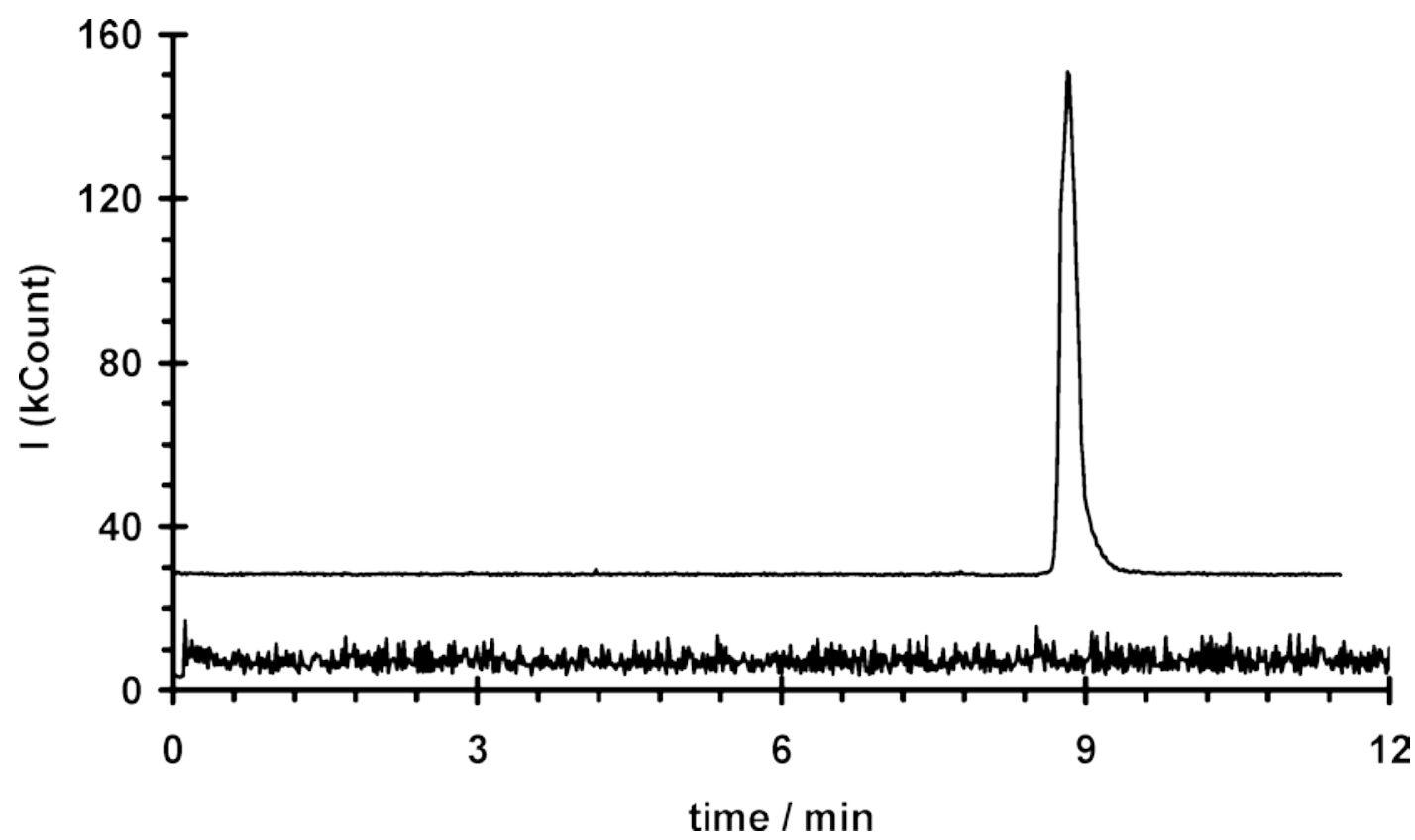

Figure 4. TD-ESI-IM-MS analysis of tube 150 prior to taking a breath sample (bottom) and tube 150 after taking a breath sample (top). The desorption rate was $12^{\circ} \mathrm{C} \mathrm{S}-1$. 

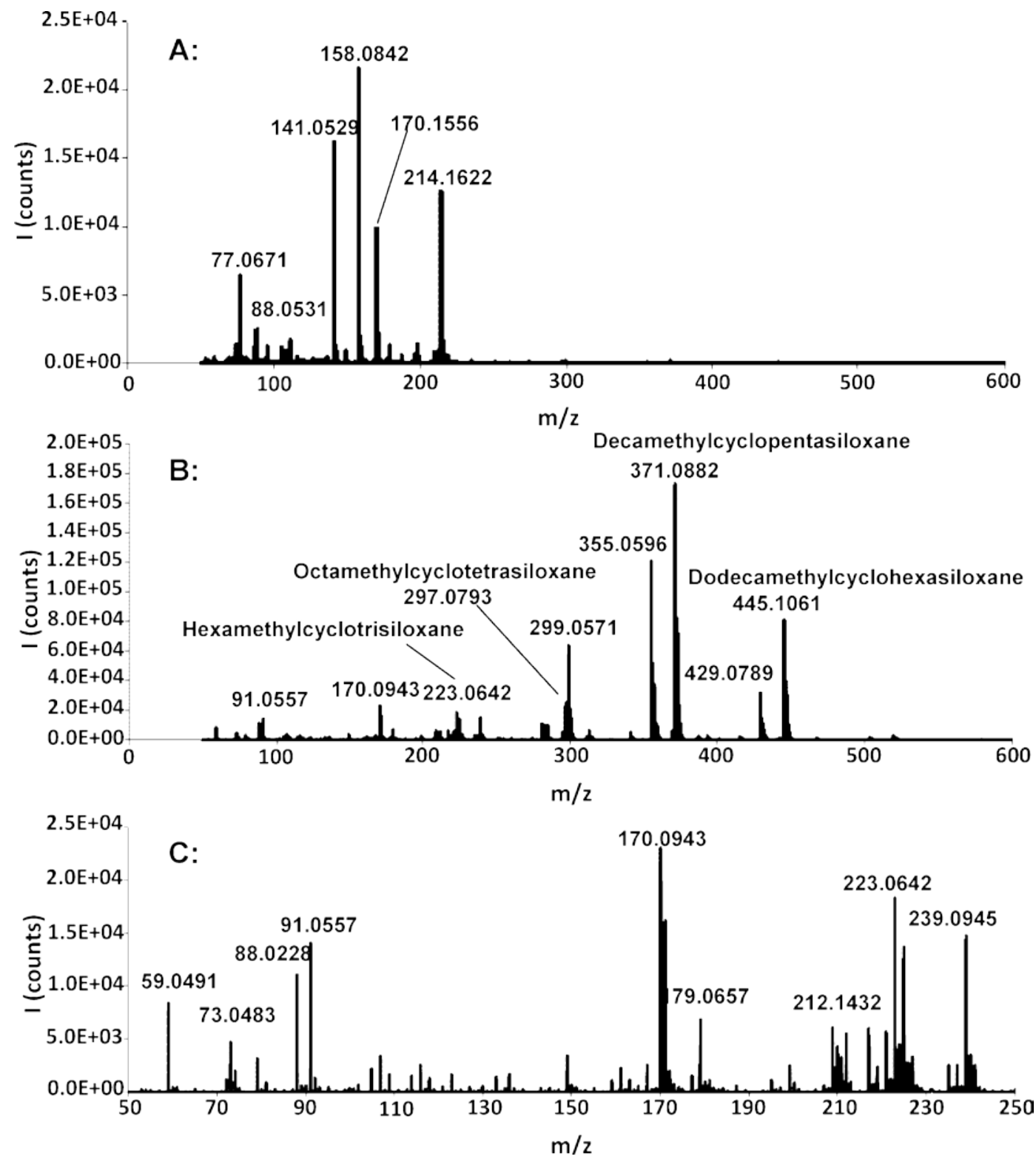

Figure 5. TD-ESI-IM-MS analysis of a breath sample from a Tenax tube (desorption rate $1{ }^{\circ} \mathrm{C} / \mathrm{s}$ ): (A) tube 483 blank mass spectrum taken prior to breath sampling, (B) mass spectrum (background subtracted) obtained from a breath sample collected on tube 483 , and (C) expanded low $\mathrm{m} / \mathrm{z}$ region of the spectrum in part $\mathrm{B}$. 

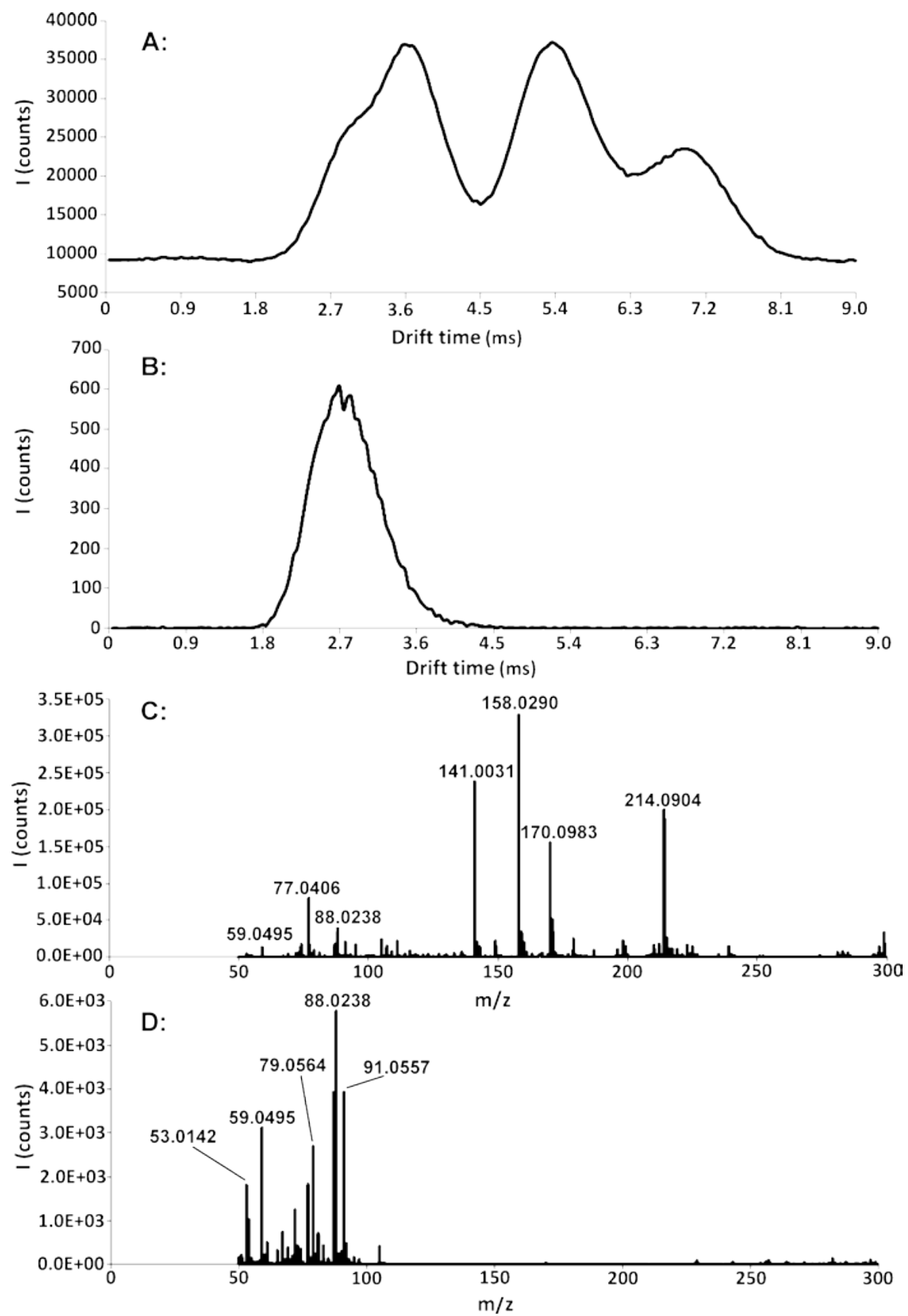

Figure 6. TD-ESI-IM-MS analysis of a breath sample from a Tenax tube (desorption rate $12{ }^{\circ} \mathrm{C} / \mathrm{s}$ ): (A) total ion mobility spectrum from a breath sample, (B) extracted ion mobility spectrum of the acetone $[\mathrm{M}+\mathrm{H}]+$ ion $(\mathrm{m} / \mathrm{z} 59.0495)$, (C) mass spectrum obtained by scanning the full IMS spectrum, and (D) mass spectrum obtained by scanning bin numbers $42-57$ of the acetone ion mobility peak. 